\title{
Research on the Coupling Mechanism of Creative Spirit Cultivation and Scientific and Technological Innovation Development
}

\author{
Ning Wang* \\ Library, The Party School of Anhui Provincial Committee (Anhui Administrative College), Hefei 230059, Anhui, China \\ *Corresponding author: Ning Wang, ss780408@126.com
}

\begin{abstract}
Migration and innovation is the driving force of scientific and technological development. By analyzing the coupling relationship between the two, this paper finds out the common elements shared by the two factors, and constructs the coupling guarantee mechanism between them, so as to provide suggestions for the coordination, win-win and synchronous benign development of the spirit of makers and the development of scientific and technological innovation, and promote the sustainable development of the national innovation system.
\end{abstract}

Keywords: Maker spirit; Nurture; Scientific and technological innovation and development; Coupling mechanism; Path

Publication date: August 2021; Online publication: August 30, 2021

1. Construction of coupling guarantee mechanism for the cultivation of creative spirit and the development of scientific and technological innovation

1.1. Innovation atmosphere - optimizing the development environment of scientific and technological innovation, and attaching importance to the innovation driving force of the maker spirit

\subsubsection{Environmental innovation}

All kinds of scientific and technological institutions and organizations should strengthen infrastructure construction, constantly optimize the innovation environment, and provide innovation driving force for the cultivation of customer spirit. Owing to the vast territory of China, the different development bases of different regions and provinces, the different layout and functional structure of various institutions and organizations, and the different development conditions and requirements, it is necessary for the government and relevant competent departments to consider the development differences of different regions, in addition to strengthening the infrastructure construction of various regions according to local conditions. We should appropriately expand some experimental or fund projects to provide a superior environment for innovation and development of science and technology. For the eastern and southern regions with high level of scientific and technological innovation and technological industry development, in addition to focusing on the efficiency of innovation and the actual utility of transformation of achievements, while strengthening technological innovation, we should constantly expand the scale of scientific and technological innovation of institutions, vigorously promote and publicize the spirit of creating customers, and offer experience for those areas and universities with relatively lagging technological development. Creating a good development environment is conducive to the innovation and growth of customers. 


\subsubsection{Organizational innovation}

The development of scientific and technological innovation cannot be separated from the support and assistance of the government, companies, universities, enterprises and other social organizations. All kinds of scientific and technological institutions should fully tap the innovative ability of all levels and organizations, pool their efforts, optimize the environment for scientific and technological innovation and development, and give full play to the innovative driving force of the spirit of creating customers. On the one hand, on the premise of defining the internal and external environment and their own development situation, scientific and technological institutions should make unified planning and deployment, eliminate duplicate construction of institutions and organizations with similar functions, maximize the value and advantages of existing institutions and organizations, and give priority to cultivating a number of innovative groups or innovation-driven development centers with strong innovative strength. They should also give full play to the radiation and driving role of the dominant group organizations. On the other hand, we should actively build and improve the "open alliance" innovation-driven collaborative development model, encourage and guide diversified institutions and organizations to cooperate, carry out innovation-driven collaborative activities involving industries, universities, research institutes, officials and funds, attach importance to the innovation coordination role of public innovation platforms, universities, scientific research institutions and large, medium and small enterprises, and improve the cooperative innovation ability of innovation subjects. In addition, all kinds of institutions should also establish market-oriented and multi-subject collaborative cross-border integration team organizations, pay attention to the construction of interdisciplinary innovation projects or key projects, promote the development of multi-disciplinary and multi-professional cross-border integration, constantly expand and strengthen the cultivation team of entrepreneurs, and organize innovation practice for entrepreneurs from the organizations so that the innovative power of the spirit of creating customers can be steadily promoted.

\subsubsection{Incentives for innovation}

The research team found that the lack of human resources and professionals seriously restricted the in-depth development of scientific and technological innovation services, especially some staff cannot fully grasp the necessary professional knowledge and business skills in a short time, putting the development of scientific and technological innovation in a dilemma, which is not conducive to the cultivation and development of the spirit of creating customers. In the future, all kinds of scientific and technological institutions should strengthen their efforts in innovating system, organization and environment, and establish a perfect and effective incentive mechanism so as to encourage employees to strengthen their professional knowledge and skills, improve the overall service quality, and provide innovation impetus to the cultivation and development of customer spirit. In addition, governments at all levels, universities, society and other institutions should attach importance to the cultivation of the spirit of makers ideologically, embrace the innovation and creativity activities of makers/makers in action, formulate relevant benefit policies and systems, safeguard the rights and interests of makers/makers, and encourage and support the innovation and creativity activities of makers in terms of system and mechanism. All kinds of institutions can be based on the performance of customers and various provincial, municipal and school-level innovation and entrepreneurship honors and awards. The number of patent authorization or technology transfer or the social promotion value of the makers' works and products, as well as a certain number of spiritual and material incentives are given to the makers/makers' groups, such as souvenirs, awards, various training certificates and award certificates. The performance of the college students' makers can be directly converted into credits. As a reference condition for endorsing for postgraduate entrance examination/doctoral entrance examination, the school should formulate relevant preferential policies to support college students who need to suspend their studies due to innovative entrepreneurship activities, 
and strive to provide a relaxed and flexible development environment for college students entrepreneurship, which are important measures to encourage and promote the spirit of creating customers, and will contribute to the development of scientific and technological innovation.

\subsection{Innovation process (innovation activities or projects) - establishing a long-term mechanism to carry forward the maker spirit}

\subsubsection{System innovation}

Scientific and technological institutions should implement various policies and measures to promote the spirit of makers and support innovation and development from the mechanism. All kinds of organizations should scientifically organize and manage maker activities, rationally design and plan around resource elements related to activities, improve and optimize accountability system, post management, information disclosure, and performance evaluation system as far as possible, ensure the stability and continuity of the policy of maker/maker group participating in innovation and entrepreneurship activities, and eliminate the "isolated island phenomenon" of minority entrepreneurship. Secondly, we should establish a "double mechanism" of fault tolerance and self-purification. First, we should actively create a good environment for innovation and fault tolerance, completely abandon the backward idea of "winner and loser," learn from experience and failure, and lay a solid foundation for turning to success ${ }^{[1]}$. Secondly, all departments should actively provide the necessary financial support for innovation and entrepreneurship groups so that students who commit mistakes in the early stage can continue to dedicate to the venture without worries. Thirdly, makers should be allowed to pilot first, facilitate the summary of experience, and gradually expand; this represents the key to the success of innovation and entrepreneurship and also the magic weapon to carry forward the spirit of makers. Creative spirit and system governance are like the relationship between fish and water; only by combining internal and external efforts, working together, fault-tolerant mechanism and self-purification mechanism of makers, perfecting the institutional system and cultivating the spirit of creators, all makers will have the courage to act and become highly focused, and become actively invested in innovation and creativity activities. It is encouraged to establish a long-term mechanism to carry forward the spirit of makers.

\subsubsection{Resource innovation}

In the process of innovation and development of scientific and technological institutions, resource innovation is essential to the cultivation of the spirit of creating customers. The main measures are:

(1) Institutions and managers should use the integration of resources to improve the efficiency of resource allocation. At the present stage, some domestic scientific and technological institutions are short in funds, talented staff, technology, equipment and so on, resulting in unreasonable allocation of resources, lack of a sound resource security system, and inability to facilitate innovative activities such as information transmission and results sharing. In the future, scientific and technological institutions should focus their superior resources on prioritized projects and innovation subjects according to their respective service characteristics, rationally allocate the supply of innovation resources, and avoid blindly investing and allocating resources that could result in serious waste of resources.

(2) We should build and improve the database of creative resources, help them obtain all kinds of academic resources, and regularly carry out resource mobilization activities. For example, the scientific and technological institutions in Beijing-Tianjin-Hebei region jointly carry out scientific and technological collaborative innovation activities after defining their respective functional orientations, constantly improve the top-level design, overall planning and management, personalize 
the design on the basis of existing service content, and provide targeted services for entrepreneurs. They also actively introduce external resources, such as alumni guidance and enterprise R\&D cooperation, to increase access to resources. They also actively create a creative idea exchange platform for individual or team makers. It is convenient for the makers to effectively utilize new technologies and acquire new knowledge in order to achieve good practical results ${ }^{[2]}$.

(3) Among all innovative resources, human resources is the most fundamental and critical. Thus, it is important to ensure that suitable talents can be allocated to every kind of innovation activities of the organization, so that the cultivation of customer spirit not only conforms to the law of human resources development, but also matches and conforms to the innovation activities or projects of the makers. To this end, scientific and technological institutions should strengthen the implementation of innovation and development policies, continue to launch a variety of innovation funding projects, direct more innovation resources to the main body of innovation, make the makers grow in the wave of innovation and creative practice, and make the cultivation of maker spirit and the development of scientific and technological innovation achieve synchronous, positive and stable growth.

\subsubsection{Skill innovation}

The main measures are as follows:

(1) Science and technology institutions should focus on personnel training to effectively link innovation and entrepreneurship education with social development, effectively gather makers from different professional backgrounds, and divide the roles of makers and implement cross-disciplinary skills training for makers/makers as the object, so as to provide technical support for the cultivation of maker spirit. They should also stimulate the vitality and creativity of makers, and truly realize innovation capability of makers. For example, Guangdong Institute of Scientific and Technological Information cooperates on the platforms of office, social interaction, learning sharing, resource docking, online and offline, actively creates a new mode of sharing scientific and technological literature resources, cooperates with universities in a low-cost and innovative mode, attracts many high-quality customer teams, and strengthens the integration of culture and science and technology. They also create conditions for innovation and skill development ${ }^{[3]}$.

(2) According to the overall planning, construction mode and service object, the organization and managers should give full play to the professional advantages of managers in knowledge retrieval, science and technology novelty search and other fields, actively export intellectual property guidance, training guidance, technical guidance and other services, and promote the formation and realization of innovative ideas.

(3) Innovation education and training should be integrated into the institutional service system in a flexible and diverse way, giving full play to the professional advantages of innovative practice, opening up a way for cultivating innovative culture, fostering the spirit of innovative practice and cultivating all kinds of innovative skilled talents.

\subsection{Innovation results (innovation achievements and evaluation and control) - improving the innovation efficiency of maker/maker team}

\subsubsection{Innovation of result}

The innovation of scientific and technological institutions is also an important driving force for the cultivation of customer spirit. Institutional organizations and managers should focus on the characteristics of the customer group and the process of innovation practice (creative prototype-creative research and development-achievement transformation). To provide corresponding services and guidance to create 
"brand" maker works and products: (i) in the embryonic stage of creativity, service personnel should carry out services such as popularization of innovation and entrepreneurship policies, innovation literacy and ability training to stimulate potential innovation consciousness of makers; (ii) in the stage of creative research and development, service personnel should timely feedback to the creative theme related to the production demand, market opportunities, scientific and technological innovation, technological feasibility and other innovation and entrepreneurship information, and ensure that R\&D projects in the right direction and track; (iii) in the stage of achievement transformation, service personnel should invite scholars and experts in competitive intelligence, innovation, application value and infringement risk to effectively protect the intellectual property rights of the achievements of the maker/maker team ${ }^{[4]}$. In addition, we should strengthen the links between the maker/maker groups and external institutions, form a team development model of innovation subjects through sharing and cooperating innovative achievements, jointly promote innovation and entrepreneurship activities, promote the transformation of achievements, improve innovation efficiency, and inherit and promote the maker spirit and its team achievements.

\subsubsection{Result evaluation and control}

The evaluation and control of the achievements of scientific and technological institutions has a farreaching impact on the cultivation of the spirit of makers. The development of scientific and technological innovation is a process of continuous promotion, which requires both innovation development and achievement evaluation, and the combination of process evaluation and outcome evaluation should be adopted to evaluate the performance of makers and their team results, so as to promote the spirit of makers. In the different stages of innovation achievement evaluation and control, organizations should take different measures: in the evaluation planning and formulation stage, managers should formulate practical planning scheme as well as implementation framework and work plan, and evaluate the progress index and effect of scientific and technological innovation ${ }^{[5]}$. In the evaluation and control, organizations and managers should implement dynamic, real-time and strict supervision of the progress of scientific and technological innovation development, timely detection of potential risks and hidden dangers, and strengthen the innovation-driven process evaluation. After the evaluation and control, we should also timely evaluate the achievements, gains and losses of innovation and development, and sum up experience and lessons. In addition, in the implementation stage of evaluation and control, we should release all kinds of information in time, grasp the operation of services in real time, and build a dynamic adjustment mechanism based on the needs of customers.

\section{Conclusions and recommendations}

The cultivation of maker spirit emphasizes the development of the creative potential of makers, the cultivation of the innovative ability and practical ability of makers. All sectors of society attach great importance to the cultivation and innovation development of maker spirit. All scientific and technological institutions should also seek, respond to and act in accordance with the situation, resonate with the wave of social development and progress together. This paper proposes that all kinds of scientific and technological institutions at all levels should deal with the coupling relationship between the two systems, identify the associated elements of the two, take measures in the path of innovation atmosphere, innovation activities or projects, innovation achievements and evaluation and control, and build a coupling guarantee mechanism between the cultivation of customer spirit and the development of scientific and technological innovation, in order to play a good role in organizational innovation, environmental innovation, institutional innovation, resource innovation. The resonance effect of "field," such as skill innovation, incentive innovation and achievement innovation will make the spirit of creating customers and the development of scientific and technological innovation achieve synchronous, positive, coordinated and win-win development. 


\section{Funding}

This paper is one of the achievements of the general projects of the National Social Science Foundation project in 2017, the project name is "Study on the Cooperative Development Mechanism Between Librarians and Creators in the Library Maker Space Service System" (item number: 17BTQ033).

\section{Disclosure statement}

The author declares that there is no conflict of interest.

\section{References}

[1] Yang J, 2018, Mechanism and Path of Coupling Development of University Science and Technology Innovation and High-tech Industry Innovation. China University Science and Technology, 2018(1): 127-31.

[2] Zhang X, 2019, Thinking on the Development of Collaborative Innovation in Beijing-Tianjin-HebeiAnalysis of the Status Quo of Collaborative Technological Innovation and Exploration of its Path. Chinese and Foreign Entrepreneurs, 2019(13): 150-3.

[3] Wang H-F, Chen L-M, 2019, Research on Guangdong Provincial Sci-tech Literature Resources Sharing Platform to Promote the Development of Innovation Ability of Sci-tech SMEs. China Science and Technology Resources Guide, 2019(6): 74-82.

[4] Su J, 2019, New Exploration on Management of Transformation of Scientific and Technological Achievements in Colleges and Universities-From the Perspective of Innovation-Driven Development Strategy. Journal of Minnan Normal University (Philosophy and Social Sciences), 2019(2): 100-5.

[5] Cao F-F, Yang H-J, 2019, Investigation and Analysis on the Current Situation of Creator Space in Chinese University Libraries. Journal of University Libraries, 2019(3): 50-6. 